\title{
Content Creation, Dissemination and Preservation: Disrupting the Status Quo through Technological Interventions
}

\author{
Subhajit Panda ${ }^{1}$ \& Rupak Chakravarty ${ }^{2}$ \\ ${ }^{1}$ Assistant Librarian, University Library, Chandigarh University, Mohali, Punjab \\ ${ }^{1}$ Email: subhajit.e9641@,cumail.in
}

\author{
${ }^{2}$ Professor, Department of Library and Information Science, Panjab University, Chandigarh \\ ${ }^{2}$ Email: rupak@pu.ac.in
}

\begin{abstract}
Disasters, either natural and man-made, adversely affect humanity including human lives and tangible assets. Knowledge as the indisputable gold standard for growth and progress of civilization also destroyed during such disasters. This should not impediment the creation of knowledge. Instead, efforts should be made to find measures which can ensure the longevity of resources for posterity. In this paper, the authors have discussed tools after evaluation and comparison which can use by learners and educators for creation, dissemination and preservation of e-content, especially multimedia. The tools acknowledged for this motive are either cost-free or the basic version is free, or it offers educators \& learners some extended free versions. This paper also highlights the resistance of Indian educators to this changing essence of learning from conventional to online.
\end{abstract}

Keywords: Disaster Management, Disruption of Knowledge Creation, Content Creation, Content Dissemination, Content Preservation, Technological Intervention

\section{INTRODUCTION:}

In the past years, the world has witnessed a significant global increase in the intensity and frequency of extreme weather events such as floods, droughts, and tropical storms, which are expected to increase even further in a future more heated climate (Field et al., 2012). The rate of development in education and research activity of a country depends upon the present economics, academic structure, research facilities, health issues and involvement of government ministry. The outbreak of present pandemic Coronavirus (official designation COVID-19 or 2019-nCov) also has a clear negative impact on academic and research activities. It creates a global threat and people keep themselves at home to maintain social distancing for reducing the outbreak of community transmission. In such situation to continue the education system smoothly and the health issue of the students are taken into most serious consideration, teaching and learning can be done using modern technologies with the help of open access tools. This is largely due to the fact that most institutions of higher education have ceased face-to-face instruction and are rapidly pivoting courses online. Learners, educators and professionals need affordable tools with steep or short learning curve for creation, dissemination and preservation of e-content, especially multimedia.

\section{SCOPE OF THE STUDY:}


[Cite as: Panda, Subhajit, \& Chakravarty, Rupak. (2020, June 27). Content Creation, Dissemination and Preservation: Disrupting the Status Quo through Technological Interventions. Presented at the National Webinar On Disaster vis-à-vis Education: Impact and Effects, Shimurali, Nadia, West Bengal, India. http://doi.org/10.5281/zenodo.4010179]

To provide a clearer picture of such tools and apps, they have been categorized into several groups. Under the content creation tools, features of LOOM, a free screen-recording app for creating highly engaging multimedia e-learning contents has been discussed. Under the dissemination or sharing platforms, a versatile and comprehensive free web-conferencing solution (FCC) has been explained which can be used by academic institutions and educators for online classes and webinars. OER Commons has been discussed as a content creation as-well-as content sharing platform for open educational resources while adopting of suitable licences as defined by Creative Commons (CC). One of the strategies for safeguarding and preventing loss from disasters is cloud storage. The paper outlines the unique features of MEGA. Online teaching and learning is incomplete without e-learning management (eLMS) system. The paper discusses the features of EDMODO a cost-effective, affordable and effective and eLMS service.

\section{TECHNOLOGICAL INTERVENTIONS (Tools for Content Creation, Dissemination and Preservation):}

\section{(A) Multimedia Content Creation:}

\section{(i) Screen Sharing Tools:}

Screen sharing is an easy yet powerful way to foster immediate collaboration, anywhere at any time. Users can to share a live video feed of what is happening on their computer's screen, with other participants of the web conference. Screenleap and Dead Simple Screen Sharing are two of the most popular and widely used screen sharing platforms. The benefits of such tools include:

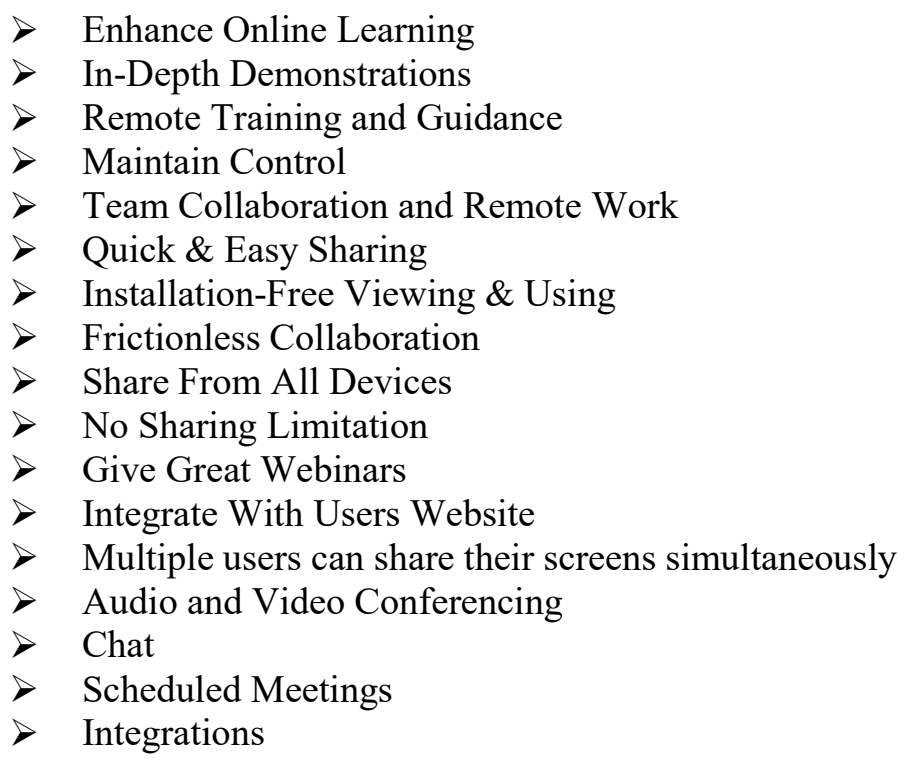

\section{(ii) Screen Recording Tools:}

Screen recording is a way of sharing a captured screen or video, recording in window or full screen modes, sharing video instructions all while allowing users to visually see the information in the same way as the sharer. 
[Cite as: Panda, Subhajit, \& Chakravarty, Rupak. (2020, June 27). Content Creation, Dissemination and Preservation: Disrupting the Status Quo through Technological Interventions. Presented at the National Webinar On Disaster vis-à-vis Education: Impact and Effects, Shimurali, Nadia, West Bengal, India. http://doi.org/10.5281/zenodo.4010179]

- Benefits: Screen recording support learning and teaching. They contain audios, images, closed captions, voiceovers, interactive elements, and other visual cues. These things are beneficial to students who prefer learning through seeing and practicing e.g. Flipped learning, blending learning, and online learning (Nguyen, 2018).

\section{(For Teachers)}

$>$ In flipped learning, the teacher early on uses a screen recording tool to make a video. Then, share the video with his learners. Students have to watch the video before coming to class. Meanwhile, class time is for discussing and doing problem-solving activities. The students thus have a deeper understanding of the lesson.

$>$ Blended learning involves online and traditional face-to-face instruction. The teacher provides online learning materials to his students. Then, the students use these resources to review and enhance their knowledge base. Note that online resources don't replace face-to-face teaching here.

$>$ Online learning (also eLearning) is different. In this case, learners take a course without meeting a teacher in a classroom setting. They can study at home or wherever they want with a computer and an Internet connection. Using eLearning authoring tools, educators create online courses with ease.

\section{(For Students)}

$>$ Screen recordings give students a combined audio-visual learning environment. They are useful to those who learn best through seeing rather than hearing or reading.

Screen recordings help improve self-study. There are a large number of free Screen recordings on YouTube, Khan Academy, Lynda, and so on.

$>$ Screen recordings allow students to learn by examples. For instance, see a step-by-step procedure in detail or easily understand a technical term through a simulation.

$>$ With Screen recordings, students become more proactive. They can learn at their own pace: watch, pause, or replay videos whenever they want. There's no need to get up early, get dressed, take a bus, you name it. Comfort is a great benefit!

> Screen recordings help improve students' attention and retention, compared to classroom and text-based learning.

Screen recordings offer students $24 / 7$ online access to knowledge. Learn anywhere and easy to review lessons before tests and exams.

$>$ Also, students create their own Screen recordings to prove what they understand. Or, record a video to share their ideas with the teacher.

\section{(a) LOOM:}

Starting from 2015, LOOM video recording software reached $\$ 73 \mathrm{M}$ in funding, $4 \mathrm{M}+$ users and installed in 90k companies with the mission to empower everyone at work to communicate more effectively and get ahead, wherever they are (Loom, n.d.-a). Loom's app lets educator easily record the screen with face before instantly sharing the link to the learners via email or message. It allows the 
[Cite as: Panda, Subhajit, \& Chakravarty, Rupak. (2020, June 27). Content Creation, Dissemination and Preservation: Disrupting the Status Quo through Technological Interventions. Presented at the National Webinar On Disaster vis-à-vis Education: Impact and Effects, Shimurali, Nadia, West Bengal, India. http://doi.org/10.5281/zenodo.4010179]

student to attend the lecture in their own personal time. With low storage and computing power requirements, Loom provide a easy way to record the lecture, edit it and send to the student with a interactive manner. The "Basic Version" of LOOM is absolutely free to use (Loom, n.d.-b), while the pro version of LOOM is absolutely free for teachers and students from accredited institutions (Loom, 2020).

\section{(b) Free Cam:}

It's a free tool for creating screen recording, edit recorded videos, and option to upload videos on YouTube without any watermark or time limits (Free Cam, n.d.).

$>$ Record Screen - Create professional video lessons and e-Learning presentations

$>$ Fine-tune Videos - Use the tool's built-in audio and video editor to turn the draft video into a well-rounded video lesson.Tools include option to delete unnecessary parts, remove background noise, and polish the audio.

$>$ Share Videos Right Away - Free Cam allows user to save the screen recording on his/her desktop or instantly share it on YouTube.

Free Cam also offers paid "Pro" version.

\section{(c) FlasBack Express:}

FlashBack (FB) is an easy screen recording tool for anyone wanting to make learning more meaningful. More and more educators are embracing new and innovative teaching methods and making instructional videos for their students to use as study aids, reinforce what they learn, and flip their classroom. It also give the option to save lecture videos on FB Connect and share links with the students, manage these videos by grouping into playlists or courses, invite students to a particular lecture videos and see who views the recording. Educator can control access to those videos and playlists, see who's watched what, track their progress and see who's finished watching it all.

A free screen recorder with advanced features (FlashBack Express, n.d.);

$>$ Capture anywhere on your PC screen

$>$ Add webcam footage to your screen recording

$>$ Add audio commentary as you record

$>$ Record movies with no watermarks

$>$ No limits on movie length

$>$ Easy sharing - upload to Youtube or download file

(B) Content Creation as-well-as Content Sharing Platform:

\section{(i) OER Commons:}

Open educational resources (OER) are teaching, learning, and research resources that reside in the public domain or have been released under an intellectual property license that permits their free use and re-purposing by others. OER include full courses, course materials, modules, textbooks, streaming videos, tests, software, and any other tools, materials, or techniques used to support access to knowledge. Open educational resources give educators the ability to adapt instructional resources 
[Cite as: Panda, Subhajit, \& Chakravarty, Rupak. (2020, June 27). Content Creation, Dissemination and Preservation: Disrupting the Status Quo through Technological Interventions. Presented at the National Webinar On Disaster vis-à-vis Education: Impact and Effects, Shimurali, Nadia, West Bengal, India. http://doi.org/10.5281/zenodo.4010179]

to the individual needs of their students, to ensure that resources are up-to-date, and to ensure that cost is not a barrier to accessing high-quality standards aligned resources (OER Commons, n.d.).

\section{- OER Licence : Creative Commons (CC)}

Open Access Licenses are free legal tool provides by Creative Commons (CC), a global nonprofit organization that enables sharing and reuse of creativity and knowledge. CC licenses restrained the strictness of Copyright from "All Rights Reserved" to "Some Rights Reserved", i.e., offer creators a spectrum of choices between retaining all rights and relinquishing all rights (public domain). This spectrum of choices evolves six basic category of CC licenses (Creative Commons, 2017), viz,

\begin{tabular}{|l|c|c|c|c|c|}
\hline CC License & $\begin{array}{c}\text { Copy \& } \\
\text { Publish }\end{array}$ & $\begin{array}{c}\text { Attribution } \\
\text { Required }\end{array}$ & $\begin{array}{c}\text { Commercial } \\
\text { Use }\end{array}$ & $\begin{array}{c}\text { Modify \& } \\
\text { Adapt }\end{array}$ & $\begin{array}{c}\text { Change } \\
\text { License }\end{array}$ \\
\hline PDM (Public Domain) & $\checkmark$ & X & $\checkmark$ & $\checkmark$ & $\checkmark$ \\
\hline $\begin{array}{l}\text { CC BY } \\
\text { (Attribute) }\end{array}$ & $\checkmark$ & $\checkmark$ & $\checkmark$ & $\checkmark$ & $\checkmark$ \\
\hline $\begin{array}{l}\text { CC BY-SA } \\
\text { (Attribution-ShareAlike) }\end{array}$ & $\checkmark$ & $\checkmark$ & $\checkmark$ & $\checkmark$ & $x$ \\
\hline $\begin{array}{l}\text { CC BY-ND } \\
\text { (Attribution-NoDerivs) }\end{array}$ & $\checkmark$ & $\checkmark$ & $\checkmark$ & $x$ & $\checkmark$ \\
\hline $\begin{array}{l}\text { CC BY-NC } \\
\text { (Attribution-NonCommercial) }\end{array}$ & $\checkmark$ & $\checkmark$ & $x$ & $\checkmark$ & $\checkmark$ \\
\hline $\begin{array}{l}\text { CC BY-NC-SA } \\
\text { (Attribution-NonCommercial- } \\
\text { ShareAlike) }\end{array}$ & $\checkmark$ & $\checkmark$ & $x$ & $\checkmark$ & $x$ \\
\hline $\begin{array}{l}\text { CC BY-NC-ND } \\
\text { (Attribution-NonCommercial- } \\
\text { NoDerivs) }\end{array}$ & $\checkmark$ & $\checkmark$ & $x$ & $x$ & $\checkmark$ \\
\hline
\end{tabular}

Figure 1. Creative Common Licenses (CC Licenses)

\section{- OER Search Engine (MOM):}

The Mason OER Metafinder (MOM) helps user find Open Educational Resources. Unlike other OER discovery sites (e.g, OER Commons, OASIS, MERLOT, OpenStax, etc.) with this Metafinder users aren't searching a static database, instead, the OER Metafinder launches a real-time, simultaneous search across 21 different sources of open educational materials as anyone hit the Search button. Because it is a real-time, federated search, it can take a bit longer than searches of pre-indexed, curated content; however, as compensation the results returned are absolutely up-to-the-minute for each search target. Additional results will continue to trickle in as the search continues running and user begin examining the results (Mason Publishing Group, n.d.).

\section{(C) Multimedia Content Dissemination or Sharing Platforms:}

\section{(i) Web-Conferencing Solution: Free Conference Call (FCC)}

FCC offers free conference calling and video conferencing with the easiest way to stay connected with colleagues and business partners from all around the world. With its easy to use technology and cost free programme, its call connection now reached over 1.5 billion people, has 800,000 users in worldwide business and hosted 40 million conferences annually. 
[Cite as: Panda, Subhajit, \& Chakravarty, Rupak. (2020, June 27). Content Creation, Dissemination and Preservation: Disrupting the Status Quo through Technological Interventions. Presented at the National Webinar On Disaster vis-à-vis Education: Impact and Effects, Shimurali, Nadia, West Bengal, India. http://doi.org/10.5281/zenodo.4010179]

FCC offers global conferencing that is flexible, straightforward and secure. No reservations required and available 24/7. There are no hidden charges. FCC meets or exceeds industry security standards, including data encryption and firewalls to protect stored data. FCC allows to host high-definition audio conferences with up to 1,000 participants using domestic or local in-country dial-in numbers or VoIP (FreeConferenceCall, n.d.-a).

Some extended features of FCC listed below (FreeConferenceCall, n.d.-a):

\begin{tabular}{|l|l|l|l|}
\hline \multicolumn{5}{|c|}{ Features of FCC } \\
\hline Conference Calls & $\begin{array}{l}\text { Video Conferencing } \\
\text { \& Screen Sharing }\end{array}$ & \multicolumn{1}{|c|}{ Meeting Wall } & $\begin{array}{c}\text { Additional Free } \\
\text { Features }\end{array}$ \\
\hline Recording & Video Conferencing & Broadcaster & 1,000 Participants \\
\hline Breakout Rooms & Screen Sharing and & Meeting Resources & Call Detail Reports \\
\hline Call Control & $\begin{array}{l}\text { Recording Controls } \\
\text { Playback }\end{array}$ & Mobile App \\
\hline Meeting Settings & Drawing Tools & Chat & Integrations \\
\hline VoIP & Remote Desktop & Radio & Calendar \\
\hline & Chat & & $\begin{array}{l}\text { History } \\
\text { Recordings }\end{array}$ \\
\hline & Studio Presentation & - & \& \\
\hline
\end{tabular}

Figure 2. Features of FCC

Hosting or joining an online class with FCC is absolutely free, helping institution \& individual to save money on software and travel costs. With a computer or smartphone and access to Wi-Fi, anyone can host or join an online meeting from anywhere with the avilability of internet access. FCC is available for download as mobile (Android and iOS) or Desktop app. If a comparative chart drawn between FCC and other known online meeting platform, following difference identified in their basic services (FreeConferenceCall, n.d.-b), 
National Webinar On Disaster vis-à-vis Education: Impact and Effects; IQAC, Shimurali Sachinandan College of Education \& Department of Education, University of Kalyani; Shimurali, Nadia, West Bengal (India)

[Cite as: Panda, Subhajit, \& Chakravarty, Rupak. (2020, June 27). Content Creation, Dissemination and Preservation: Disrupting the Status Quo through Technological Interventions. Presented at the National Webinar On Disaster vis-à-vis Education: Impact and Effects, Shimurali, Nadia, West Bengal, India. http://doi.org/10.5281/zenodo.4010179]

\begin{tabular}{|c|c|c|c|c|}
\hline $\begin{array}{l}\text { Feature/ } \\
\text { Function }\end{array}$ & FCC & GoToMeeting & Zoom & Join.me \\
\hline \multicolumn{5}{|l|}{ Service } \\
\hline $\begin{array}{l}\text { Audio } \\
\text { conferencing }\end{array}$ & $\begin{array}{l}\text { 1,000 FREE Participants } \\
\text { VolP: included } \\
\text { Toll: included } \\
\text { Toll-free: } 2 \mathrm{c} / \mathrm{min}\end{array}$ & $\begin{array}{c}50 \text { free } \\
\text { participants } \\
\text { (14-day trial) } \\
\text { Volp: included } \\
\text { Toll: included } \\
\text { Toll-free: } 8 \mathrm{c} / \mathrm{min}\end{array}$ & $\begin{array}{l}50 \text { free } \\
\text { participa } \\
\text { nts } \\
\text { (14-day } \\
\text { trial) }\end{array}$ & $\begin{array}{c}50 \text { free } \\
\text { participants } \\
\text { (14-day } \\
\text { trial) }\end{array}$ \\
\hline $\begin{array}{l}\text { Video } \\
\text { conferencing }\end{array}$ & 1,000 FREE Participants & $\begin{array}{c}50 \text { free } \\
\text { participants } \\
\text { (14-day trial) }\end{array}$ & $\begin{array}{l}100 \text { free } \\
\text { participa } \\
\text { nts }\end{array}$ & $\begin{array}{l}10 \text { free } \\
\text { participants } \\
\text { (14-day } \\
\text { trial) }\end{array}$ \\
\hline Screen sharing & 1,000 FREE Participants & $\begin{array}{c}50 \text { free } \\
\text { participants } \\
\text { (14-day trial) }\end{array}$ & $\begin{array}{l}100 \text { free } \\
\text { participa } \\
\text { nts }\end{array}$ & $\begin{array}{l}10 \text { free } \\
\text { participants } \\
\text { (14-day } \\
\text { trial) }\end{array}$ \\
\hline $\begin{array}{l}\text { Time } \\
\text { restrictions }\end{array}$ & Unlimited & $\begin{array}{l}\text { Unlimited (14-day } \\
\text { free trial) }\end{array}$ & $\begin{array}{c}40 \\
\text { minutes }\end{array}$ & $\begin{array}{l}\text { Unlimited } \\
\text { (14-day } \\
\text { trial) }\end{array}$ \\
\hline
\end{tabular}

Figure 3. Comparison between FCC \& other Video Conferencing Tools

\section{(D) e-Learning Management (eLMS) System:}

\section{(i) EDMODO:}

Edmodo is a social learning platform for students, teachers, districts, and schools. It was founded in Chicago, Illinois, and was created to usher education into the 21 st century. It has become one of the leading K-12 social learning networks in the world, dedicated to linking all students with the instructions and professionals they need to reach their full potential. In addition to modernizing the way educators interact with students, Edmodo also allows them to engage students throughout each class. Using this platform, educators will get access to all the tools they need to give the students a more exciting learning experience (Edmodo, 2005).

- Benefits: These are some of the most important benefits users experience when working with Edmodo (Henney, 2020a, 2020b);

Schools and Districts - Build a collaborative network. Become an Edmodo school or district. 
[Cite as: Panda, Subhajit, \& Chakravarty, Rupak. (2020, June 27). Content Creation, Dissemination and Preservation: Disrupting the Status Quo through Technological Interventions. Presented at the National Webinar On Disaster vis-à-vis Education: Impact and Effects, Shimurali, Nadia, West Bengal, India. http://doi.org/10.5281/zenodo.4010179]

Activate free admin account - Connect all teachers, parents, students, and administrators in a school or district through a secure Edmodo web address.

$>$ Build a network of communities - Support collaboration in schools, classrooms, and across the district to improve professional learning networks, supported by a global community of educators.

$>$ Accelerate learning goals - Easily deploy and manage digital assets, and track usage patterns and student progress on your school or district dashboard.

$>$ Gauge Student Performance - The only way to find out if educators are effectively getting through to the students is by measuring their progress.

$>$ More Learning Experience - While Edmodo already has a complete suite of online learning tools, it still offers a highly customizable and extendable interface.

$>$ Connect to resources - On Edmodo, teachers are at the center of a powerful network that connects them to students, parents, administrators, and publishers.

\begin{tabular}{|l|l|}
\hline \multicolumn{2}{|c|}{ Overview of Edmodo Features } \\
\hline Accelerate learning goals & Send an Assignment \\
\hline Activate your free admin account & Send a Quiz \\
\hline Award badges to individual students & Create a Small Group \\
\hline Build a network of communities & Add Content to Your Library \\
\hline Create polls for students & Send and View Your Direct Messages \\
\hline Measure student progress & $\begin{array}{l}\text { Moderate Student Posts \& Read Only } \\
\text { Status }\end{array}$ \\
\hline $\begin{array}{l}\text { Network that connects students, } \\
\text { administrators, parents }\end{array}$ & Manage and Remove Group Members \\
\hline Online classroom discussions & Connect Parents to your Students \\
\hline Personalize with apps & \\
\hline
\end{tabular}

Figure 4. Overview of Edmodo Features

\section{(E) Multimedia Content Preservation:}

\section{(i) Cloud Storage: MEGA}

There are several popular cloud storage services available including Google Drive, DropBox, OneDrive, etc. But as witnessed in the recent times, the requirement of cloud storage space has escalated, users want to explore cloud platforms with higher storage capabilities. MEGA is one such service which justifies the user needs comprehensively. The features and services of MEGA are being discussed below:

MEGA's core is end-to-end encrypted cloud storage and communication. In the future, MEGA will continue to develop innovative products and features that complement its existing platform for both individuals and businesses to help them improve their security on the Internet without compromising 
[Cite as: Panda, Subhajit, \& Chakravarty, Rupak. (2020, June 27). Content Creation, Dissemination and Preservation: Disrupting the Status Quo through Technological Interventions. Presented at the National Webinar On Disaster vis-à-vis Education: Impact and Effects, Shimurali, Nadia, West Bengal, India. http://doi.org/10.5281/zenodo.4010179]

on usability. MEGA has $186 \mathrm{M}+$ registered users (with $10 \mathrm{M}+$ daily active users), $77 \mathrm{~B}+$ files uploaded and 200+ countries have users on MEGA (MEGA, n.d.-a).

\section{What can you do with MEGA?}

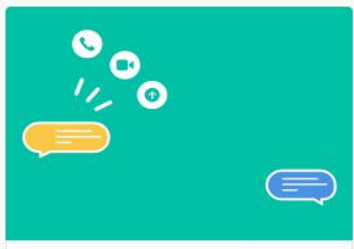

Chat securely

Connect with your contacts on MEGA and stay in touch; securely exchange messages and have audio, video or group calls with MEGAchat.

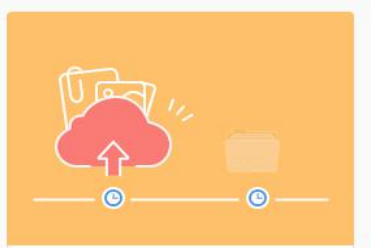

\section{Backup}

Automatically backup photos and videos from your mobile device with Camera Uploads, and sync your computer data with MEGA's Desktop App. MEGA automatically maintains historic versions of your files, allowing you to easily revert when needed.

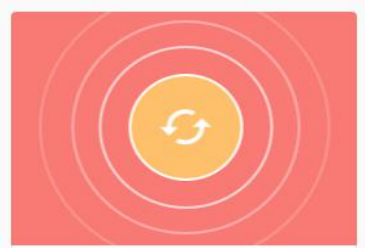

\section{Synchronize}

Easy automated synchronization between your computer and your MEGA Cloud.

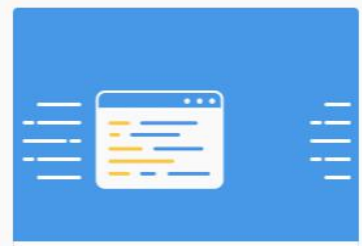

\section{Share}

Export secure links to your files and folders, or share folders directly with your contacts on MEGA.

Figure 5. MEGA Cloud Storage

- MEGA Desktop App (MEGA, n.d.-b)

$\diamond$ Major platforms: compatible with Windows, macOS and Linux, including syncing between different platforms.

$\diamond$ Stream files directly from MEGA: The MEGA app allows to stream any file from MEGA cloud.

$\diamond$ Deleted data retention: MEGA moves deleted files to a special folder on local computer and in MEGA cloud so they can be restored if required.

$\diamond$ Powerful Transfer Manager: Full control over active and completed transfers: prioritise, pause/resume, open, generate links

$\diamond$ Direct management of MEGA links, Control of network parameters.

$\diamond \quad$ Easy Automated Synchronisation: Access and work with data securely across different locations and devices with automated procedures.

$\diamond$ Synchronise entire MEGA cloud to one local folder or configure multiple selective syncs between folders on computer and folders in MEGA cloud.

$\diamond \quad$ Full end-to-end encryption (E2EE) for all transfers.

$\diamond$ Browser Integration: All MEGA browser file transfers can be automatically handled by the MEGA app, significantly enhancing the reliability, performance and speed. This avoids browser limitations, especially for large files.

$\diamond$ Browser Extensions: available for Chrome, Firefox, Opera, and Edge.

$\diamond$ File Manager: As well as syncing specified folders, users can upload and download selected files/folders, enable file versioning and overlay sync icons in your standard file explorer.

$\diamond \quad$ File Versioning. Integration with common file managers for all platforms.

- MEGA Mobile Apps (MEGA, n.d.-c)

$\diamond$ Securely manage files and collaborate with others from anywhere with secure data mobility. 
[Cite as: Panda, Subhajit, \& Chakravarty, Rupak. (2020, June 27). Content Creation, Dissemination and Preservation: Disrupting the Status Quo through Technological Interventions. Presented at the National Webinar On Disaster vis-à-vis Education: Impact and Effects, Shimurali, Nadia, West Bengal, India. http://doi.org/10.5281/zenodo.4010179]

$\diamond \quad$ Automatic Camera Uploads - Upload all photos \& videos securely for backup \& sharing directly from within MEGA.

$\diamond$ Audio/Video Streaming: MEGA decrypts media on-the-fly in the device to securely stream audio and video files directly on your phone or tablet.

$\diamond \quad$ Save Files Locally: Select files that users want to save to phone or tablet, so that they can retain access without Internet connectivity.

$\diamond \quad$ Secure and easy storage: Save files to the cloud which are transmitted \& stored securely with end-to-end encryption (E2EE) - not even MEGA can view users' files.

$\diamond$ Access files anywhere-anytime from mobile device.

$\diamond$ MEGAchat - collaborate securely and easily: MEGAchat provides text, voice and video chat with full E2EE.

a) Contact Fingerprint Verification: Verify the cryptographic fingerprint of your contacts through a separate channel to ensure they are authentic.

b) History Retention Control: Chat history and can be deleted whenever needed.

c) Secure group chat with cross-platform audio and video calls.

$\diamond$ Seamless File Sharing: Conveniently share files directly within a chat from MEGA account or from device storage.

$\diamond$ MEGA App for Windows: Universal Windows Platformin all Windows 10 devices (mobile, tablet and desktop)

Another similar cloud storage service is Degoo which provides 100GB free cloud storage as well as the mobile app.

\section{THE CHALLENGE:}

People resist change without understanding the need and importance of it and when a situation arises all should adapt to change willingly and unwillingly. This was the situation which occurred to teaching fraternity too. Indian higher education institution has used various pedagogy for innovation, development, and engagement of students. Many faculties have resisted the change when they had been asked to take virtual classes for students. And a couple of training was provided by the management of the institutions hence faculty will not face any difficulties on the same. As everything is your mindset, the faculty has to change their mindset towards the virtual classroom and adopt technology for the betterment of students (Shenoy, Mahendher, \& Vijay, 2020).

\section{CONCLUSION:}

Undoubtedly, disaster risk is a fundamental component of social and economic development, especially for low- and middle-income countries, in particular, carry a large share of the human and economic burden (Hoffmann \& Muttarak, 2017). Here the primary challenge is to reduce disaster risk and to ensure the sustainability of development in the future. If we think about knowledge creation and its disruption through any kind of disaster, the technological intervention can improve the dynamics between teachers and students, often leading to enhanced learning. This paper illustrates thoroughly how free \& open access tools help us to fight against such disaster like the recent outbreak of COVID-19 and suggest that educators and learners must be ready to adopt new changes and requirement of the present situation. 


\section{REFERENCES:}

Creative Commons. (2017, November 7). About The Licenses - Creative Commons. Retrieved June 22, 2020, from https://creativecommons.org/licenses/

Dead Simple Screen Sharing. (n.d.). Features. Retrieved June 20, 2020, fromhttps://deadsimplescreensharing.com/features

Edmodo. (2005). Edmodo: The World's Largest Learning Community. Retrieved June 24, 2020, from https://www.edmodo.com/

Field, C. B., Barros, V., Stocker, T. F., Dahe, Q., Dokken, D. J., Ebi, K. L., ... Midgley, P. M. (Eds.). (2012). Managing the risks of extreme events and disasters to advance climate change adaption: special report of the Intergovernmental Panel on Climate Change. Cambridge: Cambridge University Press.

FlashBack Express. (n.d.). A free screen recorder with advanced features. Retrieved June 21, 2020, from https://www.flashbackrecorder.com/express/

Free Cam. (n.d.). Free Tool for Creating Screencasts. Retrieved June 21, 2020, from https://www.freescreenrecording.com/

FreeConferenceCall. (n.d.-a). Features | FreeConferenceCall.com. Retrieved June 23, 2020, from https://www.freeconferencecall.com/global/in/features

FreeConferenceCall. (n.d.-b). Free Online Meetings \& Screen Sharing Software | FreeConferenceCall.com. Retrieved June 23, 2020, from https://www.freeconferencecall.com/global/in/online-meetings

Henney, K. (2020a). Students. Retrieved June 24, 2020, from https://go.edmodo.com/students/

Henney, K. (2020b). Teachers. Retrieved June 24, 2020, from https://go.edmodo.com/teachers/

Hoffmann, R., \& Muttarak, R. (2017). Learn from the Past, Prepare for the Future: Impacts of Education and Experience on Disaster Preparedness in the Philippines and Thailand. World Development, 96, 32-51. https://doi.org/10.1016/j.worlddev.2017.02.016

Loom. (2020, March 12). Loom Pro Free for Students and Teachers. Retrieved June 20, 2020, from https://support.loom.com/hc/en-us/articles/360006579637-Loom-Pro-Free-for-Students-and-Teache rs

Loom. (n.d.-a). About Us. Retrieved June 20, 2020, from https://www.loom.com/about-us

Loom. (n.d.-b). Choose the plan that's right for you or your team. Retrieved June 20, 2020, website: https://www.loom.com/pricing

Mason Publishing Group. (n.d.). About the Mason OER Metafinder (MOM) - Mason Publishing Group. Retrieved June 22, 2020, from https://publishing.gmu.edu/whos-using-the-mason-oer-metafinder/ 
[Cite as: Panda, Subhajit, \& Chakravarty, Rupak. (2020, June 27). Content Creation, Dissemination and Preservation: Disrupting the Status Quo through Technological Interventions. Presented at the National Webinar On Disaster vis-à-vis Education: Impact and Effects, Shimurali, Nadia, West Bengal, India. http://doi.org/10.5281/zenodo.4010179]

MEGA. (n.d.-a). About MEGA - The Privacy Company. Retrieved June 24, 2020, from https://mega.nz/about/main

MEGA. (n.d.-b). MEGAsync. Retrieved June 24, 2020, from https://mega.nz/sync

MEGA. (n.d.-c). Mobile Apps. Retrieved June 24, 2020, from https://mega.nz/mobile

Nguyen, V. A. (2018, September 5). Benefits of Screencasting for Teachers and Students - Atomi Systems, Inc. $\quad$ Retrieved June $\quad 21, \quad$ from https://atomisystems.com/screencasting/benefits-screencasting-for-teachers-and-students/

OER Commons. (n.d.). Frequently Asked Questions OER for K-12 Educators. Retrieved June 22, 2020,

from

https://www.oercommons.org/static/staticpages/documents/FAQ-OER-K-12.pdf?f923a5a5e335

Screenleap. (n.d.). Free Screen Sharing. Retrieved June 20, 2020, from https://www.screenleap.com/

Shenoy, V., Mahendher, S., \& Vijay, N. (2020). COVID 19 Lockdown Technology Adaption, Teaching, Learning, Students Engagement and Faculty Experience. Mukt Shabd Journal, 9(4), 698-702. Retrieved from https://www.researchgate.net/publication/340609688 